${ }^{\text {I }}$ International Institute of Social History (IISH),

Amsterdam, Holanda

mvl@iisg.nl

Marcel van der Linden'

\title{
O CONCEITO MARXIANO DE PROLETARIADO: UMA CRÍTICA
}

\section{O SUJEITO REVOLUCIONÁRIO}

Por volta de seus vinte anos, Karl Marx chegou à conclusão de que o proletariado era a única força social capaz de transcender o capitalismo. Sua Contribuição à crítica da filosofia do direito de Hegel (I843-I844) caracteriza o proletariado como

uma classe na sociedade civil que não é uma classe da sociedade civil, um estamento que é a dissolução de todos os estamentos, uma esfera que possui um caráter universal por seu sofrimento universal e que não reivindica nenhum direito particular, uma vez que nenhuma injustiça em particular, mas sim a injustiça de modo geral, lhe é perpetrada.

O proletariado é a "antítese pura" da sociedade vigente, que por sua vez é "a completa perda do homem e, portanto, só pode ganhar a si mesma através de uma completa reconquista do homem" (Marx \& Engels, I843: I86, grifos no original).

Gradualmente, a natureza da autoemancipação proletária foi se tornando mais clara para ele. Em A ideologia alemã (I845-I846) ele afirma que a abolição da sociedade burguesa demandará a apropriação coletiva de todas as forças produtivas. Isto só poderá acontecer através de

uma revolução, na qual, de um lado, o poder do modo anterior de produção e relação e a organização social sejam derrubados, e, de outro lado, o caráter universal e a energia do proletariado sejam desenvolvidos, condição para que se 
possa efetivar a apropriação, e, mesmo que o proletariado se liberte de tudo o que ainda o prende à sua prévia posição na sociedade (Marx \& Engels, I845-I846: 88).

Estas passagens de Marx estão articuladas a pelo menos quatro fatores. Primeiro, a noção de classe e luta de classes, que remonta aos debates do século XVIII. Durante as décadas que precederam a Revolução de I789, analistas sociais franceses tais como Quesnay, Turgot e outros começaram a distinguir duas ou três classes sociais. Na Grã-Bretanha, Hume, Ferguson e outros desenvolveram distinções similares quase na mesma época. Uma explicação possível para essa descoberta das classes sociais está no crescimento dos Estados nacionais, combinado com a expansão dos circuitos comerciais e as diferenças crescentes de renda que daí resultaram. Além disto, a ascensão das manufaturas e fábricas foi gradualmente impossibilitando artífices e outros trabalhadores qualificados de se tornarem empreendedores. Assim como os autores franceses e britânicos que lhe precederam, o jovem Marx não distinguiu entre "classes" e "estamentos". Na Contribuição à crítica da filosofia do direito de Hegel (I847), por exemplo, o proletariado ainda era chamado de "estamento". Mas esta confusão não durou muito. Em A miséria da filosofia (I847), o proletariado já se tornava uma "classe".

Segundo, Marx foi provavelmente influenciado por Lorenz von Stein, que em 1842 havia publicado um livro sobre O socialismo e o comunismo na França contemporânea, o qual prenunciou muito de sua teoria de classes. Para Von Stein a sociedade industrial emergente ou tornava os operários obstinados e maliciosos ou os transformava em instrumentos obtusos e subordinados servis. Ele considerava a propriedade pessoal e hereditária a causa principal deste declínio das classes trabalhadoras, uma vez que dela resultava o poder dominante de uns e a sujeição de outros (Stein, I 842: Parte I). Com observações como estas, von Stein antecipou alguns dos principais argumentos do materialismo histórico; mas,

ao contrário de Marx, ele não postulava uma revolução proletária inexorável a qual finalmente resolveria as contradições sociais. Propunha, em vez disto, uma estratégia política fundamentalmente reformista na qual o Estado guiaria a distribuição dos recursos econômicos de um modo que preveniria a polarização de classes vislumbrada por Marx (Singelmann \& Singelmann, I986: 43I).

Terceiro, Marx ficou profundamente impressionado com a revolta dos tecelões da Silésia, em I844. Em seu "Glosas críticas marginais ao artigo: 'O rei da Prússia e a reforma social. De um prussiano'” (Marx, I844: 20I) ele observa que na revolta dos tecelões silesianos,

o proletariado, de uma tacada, de modo surpreendente, claro, incontido e poderoso, proclama sua oposição à sociedade da propriedade privada. A revolta silesiana começa precisamente com o que as insurreições dos operários franceses e ingleses terminam, com a consciência da natureza do proletariado. A própria ação exibe a marca desse caráter superior. Não apenas máquinas, estas rivais dos tra- 
balhadores, foram destruídas, mas também os livros-fiscais, os títulos de propriedade. E enquanto todos os outros movimentos voltaram-se primordialmente apenas contra o dono da empresa industrial, o inimigo visível, esse movimento também está direcionado contra o banqueiro, o inimigo oculto.

Robin Blackburn (I976: 6) observou corretamente que boa parte deste artigo "ainda é escrita no antigo jargão filosófico e concerne a um argumento sobre a natureza da revolução alemã. Mas da revolta dos tecelões Marx conclui que o proletariado é o 'agente ativo' da revolução".

Quarto e último, Engels publicou seu A situação da classe trabalhadora na Inglaterra: segundo observações do autor e fontes autênticas, em I845. Tomando como base a indústria têxtil de Manchester, sugeriu que a manufatura "centraliza a propriedade nas mãos de poucos", e que, portanto, a população trabalhadora se torna centralizada, já que "um estabelecimento manufatureiro requer muitos trabalhadores empregados ao mesmo tempo em um único prédio, morando uns perto dos outros e chegando a formar um povoado no caso de uma fábrica de considerável magnitude" (Engels, I845: 325).

Combinadas, essas influências conduziram Marx à sua análise da história humana como uma história das lutas de classes que culminaria na luta de classes que acabaria com todas as lutas de classes, ou seja, a revolução proletária. A abordagem de Marx mudou para sempre o modo como pensamos os desenvolvimentos históricos e a política radical. Não obstante, o autor admitiu prontamente que muitos elementos importantes de sua teoria da revolução haviam sido antecipados por outros. Em I 852 ele escreveu a Joseph Weydemeyer:

Quanto ao que me concerne, não pretendo ter descoberto nem a existência das classes na sociedade moderna nem a luta entre elas. Muito antes de mim, historiadores burgueses descreveram o desenvolvimento histórico dessa luta entre as classes, assim como os economistas burgueses o fizeram com sua anatomia econômica. Minha contribuição específica foi I. demonstrar que a existência das classes está inextricavelmente atrelada a certas fases históricas no desenvolvimento da produção; 2. que a luta de classes leva necessariamente à ditadura do proletariado; 3. que esta ditadura constitui não mais que uma transição à abolição de todas as classes e a uma sociedade sem classes (Marx, I852: 62, 65, grifos originais).

\section{DEFININDO O PROLETARIADO}

Em nenhuma fase de sua obra Marx utiliza o termo "classe trabalhadora" de modo frequente. Preferia a noção de proletariado, um antigo conceito romano provavelmente datado do século VI a.C., que descrevia um grupo relativamente grande, mas pouco definido, de cidadãos livres e pobres, cujas proles poderiam servir como soldados para o Império (Zaniewski, I957: I5-53).

No final do século XVIII e começo do XIX, a palavra "proletariado" conheceu um ressurgimento. Inicialmente, ela foi usada de modo geral para des- 
crever a situação das pessoas sem nenhuma propriedade além da honra. Os trabalhadores eram apenas uma parte dessa massa amorfa. De acordo com o nobre francês Adolphe Granier de Cassagnac, que escrevia nos anos de I830, o proletariado formava o "nível mais baixo, o estrato mais profundo da sociedade", que consistia em quatro grupos: "os trabalhadores, os mendigos, os ladrões e as mulheres públicas":

O trabalhador é um proletário, porque ele trabalha para viver e ganhar um salário; o mendigo é um proletário, que não quer ou não pode trabalhar, e mendiga para viver; o ladrão é um proletário, que não quer trabalhar ou mendigar, e, para ganhar a vida, rouba; a prostituta é uma proletária, que não quer trabalhar, nem mendigar, nem roubar e, para viver, vende seu corpo (Granier de Cassagnac, I838: 30).

Alguns anos depois, Heinrich Wilhelm Bensen distinguiu sete categorias de proletários: além de três grupos de trabalhadores, ele também incluiu "os pobres, que estão privados do apoio dos cofres públicos", "os soldados comuns", "os ciganos, as prostitutas, os bandidos etc.", e "os pequenos servos de origem religiosa ou secular" (Bensen, I847: 344).

Pouco a pouco foi sendo feita uma diferenciação com dois resultados distintos: ou os trabalhadores declaravam que não eram proletários, mas uma classe ou estamento distinto, ou eles se identificavam com o proletariado, mas começavam a ver os outros grupos, que eram também previamente considerados proletários, como "inferiores" e "diferentes". Os trabalhadores comunis tas alemães em Londres, com os quais Marx e Engels estavam associados, tenderam à segunda opção. No Manifesto, o qual Marx e Engels foram instruídos a escrever para esses trabalhadores a partir de discussões comuns, "a classe trabalhadora moderna - os proletários" (Marx \& Engels, I848: 490) - era vista como uma unidade. Os ladrões, os mendigos e as prostitutas encontravam-se agora desvalorizados enquanto um estrato inferior, o lumpemproletariado, a

"classe perigosa", a escória social, aquela massa que apodrece passivamente, descartada pelas camadas mais baixas da velha sociedade, [que] pode, aqui ou acolá, ser arrastada ao movimento por uma revolução proletária; suas condições de vida, contudo, preparam-na bem mais para o papel de instrumento subornado de intriga reacionária (Marx, I848: 494).

A essa exclusão da parte "imoral" das classes mais baixas combinaram-se outras distinções. Para Marx era óbvio que os escravos não pertenciam ao proletariado. Desde muito cedo, os movimentos operários europeus se distanciaram de seus irmãos e irmãs escravizados. A famosa Sociedade de Correspondência de Londres (LCS), que E. P. Thompson (I963: 23) chamou de "um novo tipo de organização" de natureza operária, redefiniu sua composição, em I792, sob a influência da revolução escrava de São Domingos. Nos primeiros meses daquele ano, a LCS declarou a igualdade entre todos, "negro ou branco, de alta ou baixa condição social, rico ou pobre", mas por volta de agosto o "negro ou branco" desapareceu da agenda da sociedade, quando as notícias do Caribe 
alcançaram as ilhas britânicas. "Raça se tornou então um tema difícil e, para muitos na Inglaterra, ameaçador, de uma espécie que a liderança da LCS preferia agora evitar" (Linebaugh \& Rediker, 2000: 274). Mais tarde Marx reduziria a escravidão a uma "anomalia oposta ao próprio sistema burguês", "possível em pontos individuais do sistema burguês de produção", mas "apenas por não existir em outros pontos" (Marx, I857-I858: 464).

Marx também situou o proletariado fora da pequena burguesia. No Manifesto declara: "De todas as classes posicionadas diante da burguesia hoje, apenas o proletariado é uma classe realmente revolucionária. As outras classes entram em declínio e finalmente desaparecem diante da Indústria Moderna" (Marx \& Engels, I848: 494).

A classe média baixa, o pequeno fabricante, o comerciante, o artesão, o camponês, todas eles lutam contra a burguesia para salvar da extinção sua existência enquanto frações da classe média. Portanto eles não são revolucionários, mas conservadores [...]. Caso eles sejam revolucionários, eles o são apenas em vista de sua transferência iminente para o proletariado, [...] eles abandonam sua própria posição para se colocar na do proletariado (Marx \& Engels, I848: 494).

Assim, as fronteiras do proletariado foram demarcadas de todos os lados. A luta de classes é vista como sendo travada principalmente entre capitalistas, proprietários de terras e assalariados. As outras classes, intermediárias, são historicamente menos importantes e não exercem nenhuma função política independente; elas "entram em declínio e finalmente desaparecem diante da Indústria Moderna" (Marx \& Engels, I848: 494). Em seus escritos tardios, Marx buscou fundamentar mais extensamente esta tese. Sua crítica da economia política é, em parte, uma tentativa de circunscrever tão precisamente quanto possível a natureza histórica e as fronteiras sociais do proletariado. No primeiro volume de $O$ capital, ele finalmente define o proletário autêntico como o trabalhador que "enquanto um homem livre pode dispor de sua força de trabalho como sua própria mercadoria", e "por outro lado não possui nenhuma outra mercadoria para vender" (Marx, I867: I79).

O processo contínuo de acumulação do capital vai, de acordo com Marx, fazer com que o contingente desses trabalhadores duplamente livres cresça, tanto em termos absolutos quanto relativos, pois quanto maior o capital, de mais trabalhadores ele precisa: "Acumulação do capital implica, portanto, aumento do proletariado" (Marx, I 867: 609). A produção capitalista "reproduz em crescente extensão a classe dos trabalhadores assalariados, em que ela transforma a vasta maioria dos produtores diretos" (Marx, I 885: 40). O proletariado é recrutado "em todas as classes população":

As camadas mais baixas da classe média - os pequenos comerciantes, donos de lojas e comerciantes aposentados em geral, os artesãos e os camponeses - todos estes submergem gradualmente no proletariado, em parte porque seu diminuto capital não é suficiente para a escala na qual é conduzida a Indústria Moderna, e, 
portanto, afunda na competição com os grandes capitalistas, e em parte porque suas habilidades especializadas são tornadas sem valor pelos novos métodos de produção (Marx, I885: 492).

Consequentemente, à medida que o momento preciso da mudança revolucionária se aproxima, a sociedade capitalista se divide cada vez mais em dois grandes campos hostis.

Eu sugiro que as delimitações do proletariado feitas por Marx nem sempre derivaram de maneira lógica de sua crítica da economia política - impulsos morais, cogitações políticas e expectativas pessoais provavelmente exerceram um papel importante em suas considerações. Consequentemente, contradições significativas tornaram-se inevitáveis, enquanto fatos históricos tiveram de ser negados. Os exemplos do lumpemproletariado e dos escravos podem, sem dúvida, corroborar este ponto de discussão.

\section{EXCLUINDO O LUMPEMPROLETARIADO}

O "lumpemproletariado" fez sua aparição inicial nos primeiros escritos de Marx e Engels, em que os autores discutiram o antigo Império Romano. A noção surgiu pela primeira vez n'A ideologia alemã (I845-I846) em uma passagem discutindo o tema dos plebeus, que, estando "a meio caminho entre os homens livres e os escravos, nunca puderam ser mais que uma ralé proletária [Lumpenproletariat no original alemão]" (Marx \& Engels, I845-I846: 84). Entretanto, como conceito contemporâneo o lumpemproletariado apareceu pela primeira vez por de volta de I848-I85I, quando Marx analisou as correntes revolucionária e contrarrevolucionária francesas. Ele estava impressionado pela observação das ações e reações dos trabalhadores de ambos os lados das barricadas - um aparente absurdo que ele só podia explicar valorizando aqueles do lado certo como os proletários "reais", e desvalorizando aqueles do lado errado como pseudoproletários. ${ }^{2}$

Quando, em I85I, os trabalhadores se dividiram novamente e alguns deles apoiaram Luís Bonaparte, Marx encontrou certa justificativa para a sua análise. Em O Dezoito Brumário de Luís Bonaparte (I85I-I852), ele incluiu no lumpemproletariado não apenas os "hedonistas decadentes" de origem aristocrática ou os "ramos arruinados e aventureiros da burguesia", mas também

os vagabundos, soldados dispensados, prisioneiros libertos, escravos fugidos de navios, malandros, charlatões, lazarentos, punguistas, trapaceiros, jogadores, cafetões, donos de bordel, carregadores, literatos, tocadores de realejo, trapeiros, amoladores de faca, funileiros, mendigos - em suma, toda a massa indefinida, desintegrada, jogada aqui e acolá, denominada pelos franceses de a boemia (Marx, I85I-I852: I 49).

Esta caracterização demanda um questionamento analítico e empírico acerca de a quais grupos sociais Marx teria especificamente se referido. Ao que parece, ele teria tentado aglutinar uma série dos seguintes grupos. 


\section{Camponeses deslocados}

O Manifesto discorre sobre a "massa que apodrece passivamente, descartada pelas camadas mais baixas da velha sociedade". Provavelmente, esta é uma referência aos antigos camponeses, os quais, com o fechamento dos campos ou outras medidas, foram desapossados de seus meios de vida, migraram para as cidades e se tornaram a parte não-qualificada do proletariado moderno. Se foi isto o que Marx quis dizer, então

a diferença entre um ex-camponês recente que está se tornando um proletário em vez de um lumpemproletário parece ser mais uma questão de atitude do que de relação com os meios de produção: o proletário se tornou mais resignado em vender sua força de trabalho. Camponeses deslocados também podem figurar como "pessoas sem um negócio definido, vagabundos, gente sem lar", mas, de novo, pode-se esperar que tais pessoas se tornem proletários com o tempo (Cowling, 2002: 230)

\section{Proletários desempregados}

Um segundo grupo é formado por trabalhadores urbanos desprovidos de meios de vida - homens e mulheres que perderam seus empregos, ou estão muito velhos ou doentes para encontrar trabalho. É verdade que Marx não inclui este grupo no lumpemproletariado em O capital (Marx, I867: 637-638), mas é razoável presumir que os desempregados de longa data e outros proletários no mais baixo nível de existência tenham recorrido ao crime e à prostituição. Cowling (2002: 23I) tem razão ao dizer:

Marx é ambivalente sobre o quão fácil seria para um proletário descartado por um ramo da indústria encontrar emprego em um outro. Parte de seus escritos sobre o trabalhador como um mero apêndice da máquina sugere que se pode passar facilmente de apêndice de uma máquina para apêndice de uma outra; por outro lado, há sugestões de que as pessoas se tornam tão distorcidas por uma determinada máquina a ponto de não serem mais adequadas para trabalhar com uma outra. Além disto, pode haver problemas para aceitar a vida na fábrica de modo geral, o que significa que se deve começar a vida em uma fábrica desde jovem, tornando talvez mais fácil a mudança posterior para uma outra fábrica. Talvez esta ambiguidade corresponda à realidade da vida em meados do século XIX: uma determinada fábrica poderia envolver piores condições ou mais distorção da pessoa que outra; a demanda por força de trabalho seria maior em uma determinada época que em outra. Quaisquer dificuldades certamente levariam alguns proletários na direção de expedientes lumpen.

\section{Autoempregados}

A terceria categoria de Marx consiste de "carregadores, literatos, tocadores de realejo, trapeiros, amoladores de faca, funileiros" (Marx, I85I-I852: I49). Estes grupos têm em comum o fato de serem autônomos e de suas ocupações não serem licenciadas. Pode-se ainda conjecturar se frequentemente essas atividades não foram executadas pelos desempregados, algo atestado por estudos históricos (por exemplo, Jones, I97 I: Parte I). 


\section{Profissões dúbias}

Finalmente, temos os trapaceiros, os jogadores, os cafetões e as prostitutas. O que os une não é um tipo específico de relação de trabalho, mas a natureza presumidamente imoral de seu trabalho. "O que está em jogo aqui é que Marx parece incluir uma variedade de ocupações amplamente repudiadas para fazer o lumpemproletariado parecer menos respeitável, em vez de comprometer-se com algum tipo de análise social (ou socialista) séria" (Cowling, 2002: 232).

Não obstante estas deduções, a própria complexidade da análise de Marx apresenta alguns desafios empíricos. O sociólogo histórico Mark Traugott realizou um estudo cuidadoso e detalhado de seis batalhões (compreendendo 3.845 indivíduos) da Guarda Móvel "lumpemproletária" em I848. Ele concluiu que a composição social dos trabalhadores do lado errado das barricadas não confirma a hipótese de Marx sobre o lumpemproletariado:

Primeiro, se as ocupações autodeclaradas nos informam realmente alguma coisa é que a Guarda Móvel era composta, em sua maioria, por trabalhadores de atividades artesanais requerendo relativamente alto nível de habilidade e treinamento. Isto não nega a presença de ocupações esparsas que se adequam às descrições do lumpemproletariado. Se, por um lado, não surpreendentemente, nenhum homem da Guarda Móvel registrou entre suas ocupações prévias aquelas de cafetão, pedinte ou ladrão, por outro lado, foram registrados alguns mascates, um trapeiro, diversos músicos de rua, um mágico, um saltimbanco e alguns "sem profissão" definida. Mas mesmo no caso de se adotar uma definição ampla do estatuto de lumpemproletariado que inclua funileiros, negociantes de ferro-velho, carregadores e literatos de todos os tipos, somente se chegaria ao número de 83 indivíduos ou 3\% da amostra total (Traugott, I985: 76-77; ver, também, Caspard, 1974).

Isto indica que a análise concreta de Marx da situação francesa era enganosa. Além disto, os grupos sociais considerados lumpemproletários pelo autor certamente não foram sempre reacionários. Victor Kiernan (I972: 82), por exemplo, sustentou que o lumpemproletariado londrino, após certos períodos de aparente resignação, podia irromper como um ciclone; e uma vez em movimento, suas ações eram caracterizadas "acima de tudo [pela] audácia, espontaneidade, indiferença aos limites arbitrários no interior dos quais a sociedade cerca suas presas; uma convicção espirituosa de que a lei é estúpida". Geralmente, essas ondas de militância se seguiam às correntes de protestos por trabalhadores "comuns": "Era quando aqueles que normalmente tinham empregos sofriam crises agudas de desemprego e mostravam sinais de amotinação que os retardatários se juntavam e, eventualmente, iam além". De modo mais amplo, os "lumpemproletários" foram uma força motriz nas lutas sociais (Bovenkerk, I984). Naturalmente, isto não faz deles uma nova vanguarda, conforme se sugeriu algumas vezes (por exemplo, Fanon, I967; ver a crítica em Worsley, I972). Mas sublinha, por outro lado, que o "lumpemproletariado" não é uma categoria analítica, mas sim moral. ${ }^{3}$ 
A insustentabilidade deste conceito se torna particularmente clara no chamado Sul Global. Vic Allen sustentou corretamente que nas

sociedades onde a mera subsistência é a norma para uma grande proporção da classe trabalhadora, e onde homens, mulheres e crianças são compelidos a buscar meios alternativos de subsistência distintos dos tradicionais, o lumpemproletariado mal pode ser distinguido do restante da classe trabalhadora (Allen, I972: 188).

Conceitos vagos como "o setor informal" são uma expressão de tais condições sociais sob as quais as famílias (semi)proletárias combinam inúmeras atividades para assegurar sua sobrevivência (ver, por exemplo, Breman, I994: 3-I30).

\section{EXCLUINDO OS ESCRAVOS}

O contraste entre trabalho assalariado "livre" e escravidão é um tema recorrente na obra de Marx. Como especialista na Antiguidade europeia e contemporâneo da Guerra Civil americana, Marx era muito consciente da questão da escravidão. O primeiro volume de $O$ capital foi publicado dois anos depois da abolição da escravidão nos Estados Unidos em I865 e 2I anos antes de sua proclamação oficial no Brasil. Marx considerava a escravidão um modo de exploração historicamente atrasado destinado à desaparição, na medida em que era o trabalho assalariado "livre" que encarnava o futuro capitalista. Ele comparou as duas formas de trabalho em diversos escritos, e certamente via similaridades entre elas - ambas produziam excedentes e, "assim como o escravo, o trabalhador assalariado deve ter um senhor que o coloca para trabalhar e o governa" (Marx, I894: 384). Ao mesmo tempo, ele distinguiu algumas diferenças que eclipsavam todas as experiências que elas compartilhavam.

\section{Propriedade da força de trabalho}

A força de trabalho pode, de acordo com Marx,

aparecer no mercado como uma mercadoria apenas se, e na medida em que, seu dono, o indivíduo a quem a força de trabalho pertence, a coloca à venda, ou a vende, como uma mercadoria. Para que ele possa fazer isso, ele deve tê-la à sua disposição, deve ser o dono desimpedido de sua capacidade para o trabalho, i.e., de sua pessoa (Marx, I867: I78).

O futuro trabalhador assalariado e o dono do dinheiro "encontram-se no mercado e lidam um com o outro na base da igualdade de direitos, com a única diferença de que um é o comprador e o outro é o vendedor; sendo ambos, portanto, iguais aos olhos da lei" (Marx, I867: I78). Em outras palavras: os trabalhadores devem "possuir" sua força de trabalho e devem eles próprios oferecê-la ao mercado como uma mercadoria. Mas por que deveria ser assim? A história nos deu diversos exemplos nos quais a força de trabalho foi oferecida ao mercado, mas não pelos próprios trabalhadores. O trabalho infantil, em que os pais ou 
tutores da criança recebem os salários, é um exemplo claro disto. Os escravos de ganho, que existiram em várias partes das Américas e da África nos séculos XVIII e XIX, são outro exemplo. Um estudo brasileiro descreve a situação desses escravos (denominados ganhadores), enviados pelos proprietários para a cidade para ganhar salários, da seguinte forma:

Os ganhadores movimentavam-se livremente pelas cidades procurando trabalho. Uma prática comum, embora não generalizada, era a permissão dada pelos donos aos seus escravos para viver fora da casa do senhor em quartos alugados, tendo por vezes antigos escravos como senhorios. Eles só retornavam à casa do senhor para "pagar a semana", ou seja, para pagar a quantia semanal (por vezes diária) acordada com seus senhores. Eles podiam guardar o que excedesse essa quantia (Reis, I997: 359). ${ }^{4}$

\section{Duração da relação de trabalho}

A distinção crucial entre assalariados "livres" e escravos reside, de acordo com Marx, na duração de sua relação de trabalho. O trabalhador assalariado

deve vender [sua força de trabalho] apenas por um período definido, porque se ele for vendê-la completamente, de uma vez por todas, ele estará vendendo a si mesmo, convertendo-se de um homem livre em um escravo, de dono de uma mercadoria em uma mercadoria (Marx, I867: 178).

Pode-se chamar uma tal transação (ou seja, a "venda" gradativa de uma mercadoria, sem mudança de propriedade) de aluguel e não de venda consideração óbvia feita há muito tempo (Oppenheimer, I9I 2: I 20). ${ }^{5} \mathrm{~A}$ diferença entre vender e alugar parece insignificante, mas não é. Se A vende uma mercadoria para B, então B se torna o proprietário no lugar de A. Mas se $A$ aluga uma mercadoria para $B$, então $A$ permanece o proprietário e $B$ ganha somente o direito de usar a mercadoria por um determinado período de tempo. A "substância" da mercadoria permanece com A, enquanto B ganha seu usufruto.

Se o trabalho assalariado se baseia no aluguel, e não na compra da força de trabalho, então a diferença crucial entre um trabalhador assalariado e um escravo não é o "período definido" (Marx, I867: I78) durante o qual a força de trabalho é alienada, mas o fato de que o aluguel da força de trabalho é uma coisa e sua venda outra. Por que Marx não reconheceu isto? Provavelmente porque acarretaria uma outra configuração para a questão da criação do valor. Afinal, a substância (o valor) da força de trabalho do assalariado não seria apropriada pelo capitalista, mas permaneceria uma propriedade do trabalhador. Para Engels, o aluguel de um imóvel é "uma transferência de um valor preexistente, previamente produzido", e, portanto, "a soma total dos valores possuídos pelo senhorio e o inquilino juntos permanece a mesma que se tinha antes" (Engels, I872: 320, grifos originais). Segundo este argumento, se a relação assalariada fosse uma forma de aluguel/arrendamento um trabalhador assalariado não seria capaz de produzir mais-valia. 


\section{Capital fixo x capital variável}

Dado que a duração da relação de trabalho é vista como a principal diferença entre o assalariado e o escravo, o primeiro representa o capital variável e o segundo o capital fixo (constante). O trabalhador assalariado encarna "aquela parte do capital" que

tanto reproduz o equivalente de seu próprio valor quanto também produz um excesso, uma mais-valia, que, em dadas circunstâncias, pode variar para mais ou para menos. Esta parte do capital é continuamente transformada de magnitude constante para variável. Chamo-a, portanto, de parte variável do capital, ou, em suma, de capital variável (Marx, I867: 219, grifo original).

Os escravos são, para Marx, economicamente indistinguíveis do gado ou das máquinas: "O proprietário de escravos compra seu trabalhador como compra seu cavalo" (Marx, I867: 272). O preço de compra do escravo é seu valor de capital, e este é inevitavelmente depreciado ao longo dos anos (Marx, I894: 464). Mas, como se justifica definir apenas o trabalho assalariado como capital variável, ou seja, como "aquela parte do capital" que pode ser "maior ou menor" de acordo com as circunstâncias? O mesmo não ocorreria com o trabalho escravo produtor de mercadorias? Os preços dos escravos poderiam flutuar enormemente e estes poderiam ser vendidos a qualquer momento.

\section{Criação de valor e mais-valia}

Se um trabalhador assalariado produz mercadorias, então estas são "ao mesmo tempo valores-de-uso e valores", e, portanto, "o processo de produzi-las deve ser um processo de trabalho e ao mesmo tempo um processo de criação de valor" (Marx, I867: I96). Mas o mesmo também se aplica evidentemente para escravos cultivando cana-de-açúcar, tabaco ou índigo. Eles também produzem mercadorias, do mesmo modo que os assalariados. Portanto, os escravos também devem ter criado valor. Marx não podia admitir isto, porque os escravos eram capital fixo, e apenas o capital variável é capaz de criar valor.

Assim, a força de trabalho do assalariado é uma fonte de "mais valor do que o que ela própria possui" (Marx, I867: 204): somente porque

o trabalho preexiste na forma de trabalho assalariado, e os meios de produção na forma de capital - isto é, somente através da forma social específica destes dois fatores essenciais de produção - é que uma parte do valor (produto) aparece como mais-valia e esta mais-valia aparece como lucro (renda), como o ganho do capitalista (Marx, I894: 868).

Mais uma vez, Marx sustenta que isto não se aplica para o trabalho escravo. O proprietário de escravos pagou por seu escravo em dinheiro e, portanto, "os ganhos pelo trabalho do escravo [...] representam meramente os juros sobre o capital investido nessa compra" (Marx, I894: 6I 8). Historicamente, contudo, as plantações de cana-de-açúcar caribenhas baseadas no trabalho escravo foram extremamente rentáveis, porque o açúcar produzido tinha mui- 
to mais valor que o capital investido pelos fazendeiros (renda da terra, depreciação dos escravos, depreciação das prensas de cana-de-açúcar etc.). É realmente possível sustentar que apenas o trabalho assalariado reproduz o equivalente ao seu próprio valor e produz um montante excedente de valor (uma mais-valia)? Ou o escravo também é "uma fonte não apenas de valor, mas de mais valor do que ele próprio"?

\section{Taxa de lucro}

Segundo Marx, a taxa de lucro é tendencialmente declinante, dado o contínuo aumento da produtividade do trabalho.

Uma vez que a massa de trabalho vivo empregada está em constante declínio se comparada à massa de trabalho objetificado colocada em ação por ela, ou seja, aos meios de produção consumidos produtivamente, segue-se que a porção de trabalho vivo não paga e agregada na mais-valia também deve estar em queda contínua se comparada ao montante de valor representado pelo capital total investido (Marx, I894: 2 I I).

Naturalmente, o fim desse desenvolvimento - o colapso do capitalismo - será atingido no momento em que o capital variável estiver reduzido a zero, e o capital total consistir apenas de capital constante. Por mais paradoxal que possa parecer, se acreditarmos em Marx, esta situação futura pode já ter sido realidade nas plantações escravistas caribenhas no século XVIII, com a quase completa ausência do capital variável e a presença de uma formidável acumulação capitalista.

Inconsistências como estas revelam que a abordagem teórica do valor de Marx, privilegiando o trabalho assalariado produtivo, não foi bem fundamentada. Escravos e assalariados "livres" são mais semelhantes do que em geral se reconhece. Sob o capitalismo, existiram muitas formas intermediárias e transitórias entre ambos os modos de exploração - os ganhadores são apenas um exemplo. Mais que isto, escravos e trabalhadores assalariados "livres" executaram em muitos casos o mesmo trabalho para o mesmo capitalista (por exemplo, nas plantações brasileiras de café ou nas fábricas do sul dos EUA [ver, por exemplo, Hall \& Stolcke, I983; Whitman, I993]). Evidentemente, a força de trabalho do escravo é eterna propriedade do detentor do escravo, enquanto a força de trabalho do trabalhador assalariado é disponibilizada ao capitalista por curtos períodos de tempo. Apesar disto, não está claro por que no primeiro caso não se cria nenhum valor ou mais-valia. Já é tempo de alargar a teoria do valor trabalho de tal maneira que ela inclua a força de trabalho do escravo e de outros trabalhadores não livres com igual medida de aplicabilidade.

Não obstante, Marx parecia não estar completamente convencido de sua própria análise. Contrariando seu próprio argumento, ele frequentemente deu indicações de que também considerava a escravidão um modo de exploração capitalista. Sua hesitação pode ser constatada, por exemplo, na afirmação su- 
pracitada de que a escravidão é "uma anomalia oposta ao sistema burguês", que é "possível em pontos individuais do sistema burguês de produção", mas "apenas por não existir em outros pontos" (Marx, I857-I858: 464). No primeiro volume de $O$ capital, ao discutir a escravidão no Sul dos EUA, Marx aponta:

Mas proporcionalmente, à medida que a exportação de algodão se tornava de vital interesse daqueles estados, o sobretrabalho dos negros, e por vezes o consumo de suas vidas em 7 anos de trabalho, se tornava um fator calculado em um sistema calculista. Já não se tratava mais de obter dele uma certa quantidade de produtos úteis. Tratava-se agora da própria produção da mais-valia (Marx, I867: 244, grifos meus).

Em O capital, volume III, Marx escreveu sobre a economia escravocrata:

Todo o trabalho excedente dos trabalhadores, que aqui se manifesta no produto excedente, é extraído deles diretamente pelo proprietário de todos os instrumentos de produção, a quem pertence a terra e, sob a forma original da escravidão, os próprios produtores imediatos. Onde prevalece o ponto de vista capitalista, como nas plantações americanas, toda essa mais-valia é vista como lucro (Marx, I894: 790, grifos meus).

E nos Grundrisse ele argumentou: "Que agora não apenas os donos de plantações na América sejam descritos como capitalistas, mas que eles efetivamente o sejam, se deve ao fato de que eles existem enquanto anomalias em um mercado mundial baseado no trabalho livre" (Marx, I857-I858: 436).

Os escravos foram, portanto, uma parte integral do capitalismo e produziram mais-valia, embora isto fosse impossível porque eles encarnavam o capital fixo, e não variável.

\section{CONSEQUÊNCIAS PROBLEMÁTICAS}

A exclusão dos lumpemproletários e dos escravos não foi bem ponderada. A impressão que se tem é que Marx primeiro proclamou os trabalhadores assalariados duplamente livres como o sujeito revolucionário no campo filosófico, e depois reuniu alguns argumentos que eram em certa medida de natureza ad hoc. O resultado foi uma teoria da classe operária repleta de inconsistências lógicas e empíricas - não apenas com respeito a grupos excluídos como o lumpemproletariado e os escravos, mas também no que concerne ao próprio proletariado "real" em sentido estrito.

Em primeiro lugar, a maior parte dos movimentos "proletários" da época de Marx não partiu dos assalariados duplamente livres como ele pensava. Os tecelões silesianos, que em I844 revelaram a Marx o potencial revolucionário do proletariado, não eram "trabalhadores" no sentido marxiano. Eles eram aldeões que trabalhavam por conta própria representando "formas embrionárias" do trabalho assalariado capitalista (Marx, I972: 422-423): "eles detinham os meios de produção e obtinham somente as matérias-primas de comerciantes atacadistas". Isto não pretende negar, é claro, que esses tecelões - que eram em sua maioria mulheres (Notz, 2009) - 
viviam em constante dependência dos comerciantes atacadistas. Quando o preço do algodão caía, as perdas eram repassadas para os tecelões sob a forma de cortes salariais. A superabundância de trabalho e uma escassez de capital da parte dos trabalhadores significava que os comerciantes capitalistas estavam em posição de ditar quase livremente o nível dos salários e as condições de trabalho (Von Hodenberg, 2002: 4I; I997: cap. 2).

Os operários comunistas da Liga dos Comunistas em Londres, que solicitaram a Marx e Engels a elaboração do Manifesto, eram principalmente artífices semiproletarizados trabalhando em oficinas artesanais e sob sistemas de subcontratação, ou sweating systems (Brandenburg, I977: cap. VII). A base social da Social Democracia Alemã à época de Marx talvez possa ser melhor caracterizada como um "movimento popular de pequenos produtores" (Welskopp, 2000: 60-228). A base da Comuna de Paris era algo semelhante (Gould, I995: cap. 6; indicações já presentes em Rougerie, I964). Além disto, Marx superestimou muito a concentração dos trabalhadores britânicos em grandes oficinas (Samuel, I977). A pesquisa histórica indica que durante o século XIX os trabalhadores empregados por grandes fábricas da grande indústria tiveram um papel menos significativo nos movimentos operários do que os que trabalhavam por conta própria e os artesãos. ${ }^{6}$

Em segundo lugar, Marx superestimou o ritmo e a dimensão da proletarização. Ao afirmarem no Manifesto comunista, por exemplo, que na "sociedade existente, a propriedade privada já está extinta para nove décimos da população; sua existência para poucos deve-se unicamente à sua não-existência para aqueles nove décimos" (Marx \& Engels, I848: 500), Marx e Engels estavam apenas exprimindo uma expectativa. Tratou-se claramente de um exagero: "Por volta de I848, essa situação não existia nem na avançada Inglaterra, quanto menos na França ou na Alemanha" (Mauke, I970: I I8). Posteriormente, a plena proletarização progrediu muito nos países capitalistas avançados - embora tenham existido contratendências, tais como o ressurgimento da meação e do trabalho autônomo (Wells, I984; Steinmetz \& Wright, I989; Bögenhold \& Staber, I99I). Mesmo assim, a expansão mundial do capitalismo na África, Ásia e América Latina resultou apenas em pequena medida no crescimento de um proletariado "puro": "em termos de classe, o padrão do desenvolvimento capitalis ta na periferia foi incapaz de seguir a lógica da plena 'proletarização' vigente no centro" (Post, I997: 5; ver, também, Amin \& Van der Linden, I996).

Em terceiro lugar, Marx subestimou a habilidade do capitalismo em incorporar o proletariado. Como vimos, Marx considerava o proletariado "uma classe na sociedade civil que não é uma classe da sociedade civil". Entretanto, o fato é que gradualmente o proletariado se tornou uma parte da sociedade civil. Pelo menos três influências, não previstas por Marx, atuaram provavelmente nesse processo: (i) A incorporação política do proletariado, que resultou em parte dos esforços dos movimentos operários. Para o caso britânico, Bert Moorhouse (I973: 346) sustentou que "a maioria da classe dominante acredi- 
tava que a incorporação era necessária para ligar as massas ao sistema prevalente, mas também pretendia que tal integração fosse condicionada e canalizada de tal maneira que, mesmo que as formas institucionais mudassem, e fossem anunciadas como tendo mudado, a distribuição diferencial do poder na sociedade permaneceria a mesma"; (ii) A incorporação dos proletários como consumidores. É verdade que Marx, nos Grundrisse, chamou a atenção para o empenho dos capitalistas em estimular os trabalhadores "ao consumo, dotando suas mercadorias com novos atrativos para despertar nos trabalhadores o sentimento de novas necessidades etc." (Marx, I857-I858: 217), mas em parte alguma ele demonstra ter entendido as enormes implicações dos grilhões de ouro do proletariado (Lebowitz, 2009: 308); (iii) Mudanças tecnológicas dos processos de trabalho tiveram uma dupla consequência: “(a) uma redução drástica (e contínua) no componente produção/trabalhador, e (b) uma vasta proliferação das categorias de trabalho nos setores de distribuição e serviço da economia" (Sweezy, I967: 37; Edwards, I985).

\section{CONCLUSÃO}

A teoria do proletariado de Marx requer uma séria reconsideração. Sua delimitação teórica do proletariado frente a outros grupos subalternos (os autônomos e os escravos) é inconsistente; as análises de classes baseadas nessa teoria têm sido amplamente refutadas pela pesquisa empírico-histórica; e sua previsão do crescimento do proletariado somente se confirmou parcialmente por desenvolvimentos tardios.

Indubitavelmente, necessitamos de uma nova conceituação do proletariado baseada antes na inclusão que na exclusão. Tal conceituação pode ser atingida de duas maneiras. Uma opção é suprimir a ideia de "anomalias" e considerar todas as formas de trabalho orientadas para o mercado (inclusive o trabalho não-livre) como variações do trabalho para o capital. Esta é a posição defendida por Jairus Banaji e Rakesh Bhandari. Ela implica que as diferenças entre escravos, meeiros e assalariados são de natureza apenas gradual, uma vez que todos eles trabalham para o capital por imposições de ordem econômica e/ou não-econômica:

Encontrar a essência do trabalho assalariado em atividades do capital não apenas permite uma mudança na extensão do conceito, apresentando por essa via um desafio à oclusão apologética eurocêntrica da escravidão e do colonialismo na escrita da história do capitalismo, mas permite também colocar em relevo o modo pelo qual o trabalho assalariado é, ele próprio, sob quaisquer de suas formas, escravizado (Bhandari, 2008: 96; 2007; Banaji, 2010).

Uma outra opção é alargar o conceito de proletariado de modo a incluir todas as formas de trabalho mercantilizado. Desta perspectiva, o proletariado consiste de todos os portadores de força de trabalho a qual é vendida ou alu- 
gada a empregadores (incluindo indivíduos, corporações e instituições) sob imposições de ordem econômica ou não-econômica, independente de serem os próprios portadores que vendem ou alugam sua força de trabalho ou não; e independentemente de serem os próprios portadores os donos dos meios de produção (Van der Linden, 2008: cap. 2). Naturalmente, todos os aspectos desta definição provisória exigem maior reflexão. No entanto, esta delimitação conceitual indica a base de classe comum a todos os trabalhos subalternos: a mercantilização coerciva de sua força de trabalho.

Em ambas as abordagens, todos os componentes do proletariado assim redefinido compartilham sua exploração por empregadores e a mercantilização de sua força de trabalho. Compartilham, portanto, um interesse de classe comum pela transcendência do capitalismo. Pesquisas históricas recentes revelaram, por exemplo, casos concretos de lutas conduzidas em conjunto por escravos e assalariados "livres" (por exemplo, Linebaugh \& Rediker, 2000). Ao mesmo tempo, os interesses de curto e médio prazos de segmentos desse proletariado de amplo espectro podem divergir fortemente. Esta redefinição do proletariado tem um preço, entretanto. Se aceitarmos que não apenas os assalariados "livres" são parte integral do capitalismo, mas também os escravos e outros grupos de trabalhadores, então tanto o capital variável (trabalhadores "livres") quanto o capital fixo (escravos) são capazes de produzir valor e mais-valia. Uma nova teoria do valor será então necessária. ${ }^{7}$

Recebido em I8/I I/20I4 | Aprovado em I8/03/20I5

Marcel van der Linden é Pesquisador Colaborador Sênior do International Institute of Social History (IISH), instituição na qual ele foi diretor de pesquisa entre 200I e 20I4. É o presidente fundador da Associação Internacional de História Social (200520I0, 2010-20I5), membro fundador da Associação de Historiadores

do Trabalho Indiano (I996), fundador da Rede de História do Trabalho Europeu (ELHN) em 2013, além de editor ou coeditor de um grande número de revistas acadêmicas no campo da história social. É também coeditor da Marx-Engels Gesamtausgabe (MEGA). Entre seus trabalhos recentes estão Beyond Marx. Theorising global labour relations in the twenty-first century (2013), coeditado com Karl Heinz Roth; e Trabalhadores do mundo: ensaios para uma história global do trabalho (2014). 


\section{NOTAS}

I É interessante que Marx, n'O capital, volume I, se refira implicitamente à classificação de Granier de Cassagnac e fale de "vagabundos, criminosos, prostitutas, em suma, as classes 'perigosas'” (Marx, I867: 637).

2 Isto levou a uma certa ambivalência: os trabalhadores "errados" eram e não eram proletários. Hal Draper destaca este ponto e observa "uma certa ambivalência na questão de se o lumpemproletariado deve ser considerado uma parte do proletariado ou não" (Draper, I972: 2294). Em Lutas de classes na França (I850) é possível ler, por exemplo, que os componentes da Guarda Móvel contrarrevolucionária "pertenciam, em sua maioria, ao lumpemproletariado, que em todas as grandes cidades forma uma massa agudamente diferenciada do proletariado industrial [...]". Apenas algumas linhas abaixo, Marx escreve, contudo, que "o proletariado de Paris foi confrontado com um exército, extraído de seu próprio meio" (Marx, I850: 62).

3 No final do século XIX e começo do XX, o conceito de "lumpen" se tornou fundamental para a eugenia socialista (Schwartz, I994).

4 Marx estava ciente da existência de escravos de ganho, mas ele não tirou nenhuma conclusão teórica disso. Ver, por exemplo, Marx (I894: 464): "Sob um sistema escravocrata, o trabalhador tem um valor capital, a saber, seu preço de compra. E quando ele é alugado, aquele que aluga deve pagar em primeiro lugar os juros sobre esse preço de compra e, além disso, repor o desgaste anual do capital".

5 Marx viu a analogia entre trabalho assalariado e processo de aluguel. Compare-se, por exemplo, seu comentário de que "O preço da força de trabalho é fixado por contrato, embora ele só seja efetivado mais tarde, como o aluguel de uma casa" (Marx, I867: I85).

6 Por um lado, Marx considerava "verdadeiros" proletários certos trabalhadores que não eram qualificados, por outro lado ele por vezes excluía do proletariado trabalhadores que deveriam ter sido incluídos de acordo com a sua própria análise. Quando discute, por exemplo, o excedente populacional relativo n'O capital, volume I, Marx considera as prostitutas uma parte importante do lumpemprole- 
tariado efetivo (Marx, I867: 637). Em outros lugares, especialmente nas Teorias da mais-valia (por exemplo, Marx, I86I-I863: 2I-22), Marx afirma que as prostitutas, quando trabalham para um cafetão, exercem trabalho assalariado (improdutivo), como atores ou músicos, e são, portanto, por implicação, parte do proletariado no sentido estrito do termo.

7 Observe-se que de um ponto de vista lógico: "A teoria da mais-valia é [...] desnecessária para a sustentação moral que os marxistas fazem quando dizem que o capitalismo é explorador" (Cohen, I988: 2I4).

\section{REFERÊNCIAS BIBLIOGRÁFICAS}

Allen, Vic L. (1972). The meaning of the working class in Africa. Journal of Modern African Studies, Io/2, p. I69-I89.

Amin, Shahid \& Van der Linden, Marcel (orgs.). (1996). "Peripheral" labour? Studies in the history of partial proletarianization. Cambridge: Cambridge University Press.

Banaji, Jairus. (2010). Theory as history: Essays on modes of production and exploitation. Leiden/Boston: Brill.

Bensen, Heinrich W. (1847). Die Proletarier. Eine historische Denkschrift. Stuttgart: s. n.

Bhandari, Rakesh. (2008). The disguises of wage-labour: Juridical illusions, unfree conditions and novel extensions. Historical Materialism, I6/I, p. 7I-99.

Bhandari, Rakesh. (2007). Slavery and wage labor in history. Rethinking Marxism, I9/3, p. 396-408.

Blackburn, Robin. (I976). Marxism: Theory of proletarian revolution. New Left Review, 97, p. 3-35.

Bögenhold, Dieter \& Staber, Udo. (I99I). The decline and rise of self-employment. Work, Employment and Society, 5, p. 223-239.

Bovenkerk, Frank. (I984). The rehabilitation of the Rabble: How and why Marx and Engels wrongly depicted the lumpenproletariat as a reactionary force. The Netherlands Journal of Sociology, 20/I, p. I3-4I.

Brandenburg, Alexander. (1977). Theoriebildungsprozesse in der deutschen Arbeiterbewegung, I835-I850. Hannover: SOAK-Verlag. 
Breman, Jan. (1994). Wage hunters and gatherers. Search for work in the urban and rural economy of South Gujarat. Nova Deli: Oxford University Press.

Caspard, Pierre. (1974). Aspects de la lutte des classes en I848: le recruitement de la garde nationale mobile. Revue Historique, 5I I, p. 8I-Io6.

Cohen, Gerald A., (1988). The labour theory of value and the concept of exploitation. In: History, labour and freedom. Themes from Marx. Oxford: Clarendon Press, p. 209-238.

Cowling, Mark. (2002). Marx's lumpenproletariat and Murray's underclass: Concepts best abandoned?. In: Cowling, Mark \& Martin, James (orgs.). Marx's Eighteenth Brumaire: (post)modern interpretations. Londres: Pluto Press, p. 228-242. Draper, Hal. (I972). The concept of the "lumpenproletariat" in Marx and Engels. Economies et Sociétés, VI/I 2, p. 228523 I 2 .

Edwards, Richard. (1985). Sweezy and the proletariat. In: Resnick, Stephen \& Wolff, Richard (orgs.). Rethinking Marxism. Struggles in Marxist theory. Essays for Harry Magdoff and Paul Sweezy. Brooklyn: Autonomedia, p. 99-I I4.

Engels, Frederick. (1872). The housing question. In: Marx \& Engels Collected Works (vol. 23). Disponível em <https:// marxists.anu.edu.au/archive/marx/works/cw/volume23/ index.htm>. Acesso em 27 jan. 2016.

Engels, Frederick. (1845). Condition of the working class in England. In: Marx \& Engels Collected Works (vol. 4). Disponível em <https://marxists.anu.edu.au/archive/marx/ works/cw/volumeo4/index.htm>. Acesso em 26 jan. 20 I6. Fanon, Frantz. (1967). The wretched of the Earth. Prefácio de Jean-Paul Sartre. Tradução de Constance Farrington. Harmondsworth: Penguin.

Gould, Roger V. (I995). Insurgent identities: Class community, and protest in Paris from 1848 to the commune. Chicago: University of Chicago Press.

Granier de Cassagnac, Adolphe. (1838). Histoire des classes ouvrières et des classes bourgeoises. Paris: Desrez.

Hall, Michael \& Stolcke, Verena. (I983). The introduction of free labour on São Paulo coffee plantations. Journal of Peasant Studies, Io/2-3, p. I70-200. 
Herrnstadt, Rudolf. (1965). Die Entdeckung der Klassen. Die Geschichte des Begriffs Klasse von den Anfängen bis zum Vorabend der Pariser Julirevolution I 830. Berlim: VEB Deutscher Verlag der Wissenschaften.

Hodenberg, Christina von. (2002). Weaving survival in the tapestry of village life. Strategies and status in the Silesian Weaver Revolt of I 844. In: Kok, Jan (org.). Rebellious families. Household strategies and collective action in the nineteenth and twentieth centuries. Nova York e Oxford: Berghahn, p. 39-58. Hodenberg, Christina von. (I997). Aufstand der Weber. Die Revolte von I 844 und ihr Aufstieg zum Mythos. Bonn: Dietz.

Jones, Gareth Stedman. (I97I). Outcast London. A study in the relationship between classes in Victorian society. Oxford: Clarendon Press.

Kiernan, Victor. (I972). Victorian London. Unending purgatory. New Left Review, 76, p. 73-90.

Lebowitz, Michael A. (2009). Following Marx: Method, critique and crisis. Leiden e Boston: Brill.

Linebaugh, Peter \& Rediker, Marcus. (2000). The Many-Headed Hydra. Sailors, slaves, commoners, and the hidden history of the revolutionary Atlantic. Boston: Beacon Press.

Marx, Karl. (1894). Capital, volume III. In: Marx \& Engels Collected Works (vol. 37). Disponível em <https://marxists.anu. edu.au/archive/marx/works/cw/volume37/index.htm>. Acesso em 27 jan. 2016.

Marx, Karl. (1885). Capital, volume II. In: Marx \& Engels Collected Works (vol. 36). Disponível em <https://marxists.anu. edu.au/archive/marx/works/cw/volume36/index.htm>. Acesso em 27 jan. 2016.

Marx, Karl. (1867). Capital, volume I. In: Marx \& Engels Collected Works (vol. 35). Disponível em <https://marxists.anu. edu.au/archive/marx/works/cw/volume35/index.htm>. Acesso em 27 jan. 2016.

Marx, Karl. (I86I-I863). A contribution to the critique of Political Economy. In: Marx \& Engels Collected Works (vol. 3I). Disponível em <https://marxists.anu.edu.au/archive/marx/ works/cw/volume3I/index.htm>. Acesso em 27 jan. 2016.

Marx, Karl. (1857-I858). Economic manuscripts of I857-58. (First part of the Grundrisse). In: Marx \& Engels Collected 
Works (vol. 28). Disponível em <https://marxists.anu.edu. $\mathrm{au} /$ archive/marx/works/cw/volume28/index.htm>. Acesso em 27 jan. 2016 .

Marx, Karl. (I852). Letter to Joseph Weydemeyer in New York. In: Marx \& Engels Collected Works (vol. 39). Disponível em <https://marxists.anu.edu.au/archive/marx/ works/I852/letters/52_03_05.htm>. Acesso em 27 jan. 2016. Marx, Karl. (I850). The class struggles in France, I 848 to I 850. In: Marx \& Engels Collected Works (vol. Io). Disponível em <https://marxists.anu.edu.au/archive/marx/works/cw/ volumero/index.htm>. Acesso em 27 jan. 2016.

Marx, Karl. (1844). Critical notes on the article: "The king of Prussia and social reform. By a Prussian". In: Marx \& Engels Collected Works (vol. 3). Disponível em <https://marxists.anu.edu.au/archive/marx/works/ I 844/08/07.htm> Acesso em 27 jan. 2016.

Marx, Karl. (I843). A contribution to the critique of Hegel's Philosophy of Right: Introduction. In: Marx \& Engels Collected Works (vol. 3). Disponível em <https://marxists.anu. edu.au/archive/marx/works/I843/critique-hpr/intro.htm>. Acesso em 27 jan. 2016.

Marx, Karl \& Engels, Frederick. (I848). Manifesto of the Communist Party. In: Marx \& Engels Collected Works (vol. 6). Disponível em <https://marxists.anu.edu.au/archive/marx/ works/cw/volumeo6/index.htm>. Acesso em 27 jan. 2016. Marx, Karl \& Engels, Frederick. (I845-I846). The German ideology. In: Marx \& Engels Collected Works (vol. 5). Disponível em <https://marxists.anu.edu.au/archive/marx/ works/cw/volumeo5/index.htm>. Acesso em 27 jan. 2016. Mauke, Michael. (1970). Die Klassentheorie von Marx und Engels. Frankfurt/Main: Europäische Verlagsanstalt.

Moorhouse, Herbert F. (I973). The political incorporation of the British working class: An interpretation. Sociology, 7, p. 34I-359.

Notz, Gisela. (2009). Warum der Weberaufstand kein Weberinnenaufstand war. In: Bitzegeio, Ursula, Kruke, Anja \& Woyke, Meik (orgs.). Solidargemeinschaft und Erinnerungskultur im 20. Jahrhundert. Beiträge zu Gewerkschaften, Nationalsozialismus und Geschichtspolitik. Bonn: Verlag J. H. W. Dietz Nachf., p. 97-I I 7 . 
Oppenheimer, Franz. (I9I2). Die soziale Frage und der Sozialismus. Eine kritische Auseinandersetzung mit der marxistischen Theorie. Jena.

Post, Ken. (1997). Revolution's other world. Communism and the periphery, I 917-39. Houndmills: Macmillan.

Reis, João José. (I997). "The revolution of the ganhadores": Urban labour, ethnicity and the African strike of 1857 in Bahia, Brazil. Journal of Latin American Studies, 29, p. 355-393. Rougerie, Jacques. (I964). Composition d'une population insurgée: L'example de la Commune. Le Mouvement Social, 48, p. 3 I-47.

Samuel, Raphael. (1977). The workshop of the world: Steam power and hand technology in mid-Victorian Britain. History Workshop Journal, 3/I, p. 6-72.

Schwartz, Michael. (I 994). "Proletarier" und "Lumpen": Sozialistische Ursprünge eugenischen Denkens. Vierteljahrshefte für Zeitgeschichte, 42, p. 537-570.

Singelmann, Joachim \& Singelmann, Peter. (I986). Lorenz von Stein and the paradigmatic bifurcation of social theory in the nineteenth century. British Journal of Sociology, 37/3, p. 43I-452.

Stein, Lorenz von. (1842). Der Socialismus und Communismus des heutigen Frankreichs. Ein Beitrag zur Zeitgeschichte. Leipzig: Wigand.

Steinmetz, George \& Wright, Erik Olin. (1989). The fall and rise of the petty bourgeoisie: Changing patterns of selfemployment in the postwar United States. American Journal of Sociology, 94/5, p. 973-Ior 8.

Sweezy, Paul. (1967). Marx and the proletariat. Monthly Review, I9/7, p. 25-42.

Thompson, Edward P. (1963). The making of the English working class. Londres: Victor Gollancz.

Traugott, Mark. (1985). Armies of the poor. Determinants of working-class participation in the Parisian insurrection of June I 848. Princeton: Princeton University Press.

Van der Linden, Marcel. (2008). Workers of the world. Essays toward a global labor history. Leiden/Boston: Brill.

Wells, Miriam J. (I984). The resurgence of sharecropping: Historical anomaly or political strategy?. American Journal 
of Sociology, 9o/I, p. I-29.

Welskopp, Thomas. (2000). Das Banner der Brüderlichkeit. Die deutsche Sozialdemokratie vom Vormärz bis zum Sozialistengesetz. Bonn: Dietz.

Whitman, T. Stephen. (1993). Industrial slavery at the Margin: The Maryland chemical works. Journal of Southern History, 59/I, p. 3I-62.

Worsley, Peter. (I972). Frantz Fanon and the "lumpenproletariat". The Socialist Register, p. 193-230.

Zaniewski, Romuald. (I957). L'origine du prolétariat romain et contemporain. Faits et theories. Louvain/Paris: Editions Nauwelaerts and Béatrice Nauwelaerts. 


\section{O CONCEITO MARXIANO DE PROLETARIADO: UMA CRÍTICA}

\begin{abstract}
Resumo
A teoria marxiana do proletariado exige uma séria reconsideração. Sua delimitação teórica do proletariado frente a outros grupos subalternos (o lumpemproletariado e os escravos) é inconsistente; as análises das classes concretas baseadas nessa teoria foram amplamente refutadas pela pesquisa empírico-histórica; e sua previsão do crescimento do proletariado somente se confirmou parcialmente por desenvolvimentos tardios. Indubitavelmente, necessitamos de uma nova conceituação do proletariado baseada antes na inclusão que na exclusão.
\end{abstract}

\section{THE MARXIAN CONCEPTION OF THE PROLETARIAT: A CRITIQUE}

Abstract

Marx's theory of the proletariat is in need of serious reconsideration. Its theoretical demarcation of the proletariat with regard to other subaltern groups (the lumpenproletariat and chattel slaves) is inconsistent; the concrete class analyses based on this theory have, to a significant extent, been refuted by empirical historical research; and its forecast of the growth of the proletariat has only been confirmed partly by later developments. Arguably, we need a new conceptualisation of the proletariat that is based on inclusion rather than exclusion
Palavras-chave

Marx;

Proletariado;

Lumpemproletariado;

Escravos;

Definição de classe

trabalhadora;

Keywords

Marx;

Proletariat;

Lumpenproletariat;

Slaves;

Definition of

working class; 